\title{
E-Communitarianism, Democracy and Environmental Education: Brief Notes
}

\section{López Velasco $S^{*}$}

Department of Philosophy, Federal University of Rio Grande, Brazil

*Corresponding author: Sirio López Velasco, Professor, Doctor of Philosophy, co-founder of the Master of Environmental Education and Doctorate/ Federal University of Rio Grande, Campus Carreiros, Brazil, Email: lopesirio@hotmail.com

E-communitarian democracy is supported by and needs widespread e-communitarian environmental education. It includes both formal education (we refer to what currently includes educational centers, from maternal-infant to university), and in non-formal education (which is what takes place in various homey forms, in the most diverse modes of communication, and in the simple interactions between humans during their various activities). Such education, based always on the latest research in neuroscience and psychology indicating the best age and way to approach each question, will promote the knowledge, reflection and daily application of the three fundamental ethical standards and the guidelines and forms of social action that the community has erected from them. The goal is ceaselessly to reinforce and improve e-communitarianism and its guiding principle: "from each according to his ability and to each according to his need, respecting ecological balance and interculturality".

Such education is problematizing (in the sense of Freire's Pedagogy of the Oppressed); i.e., in a critical way, it constantly reveals existing social oppression and environmental devastation, aiming at overcoming them in a community that lacks inter-human oppression and in which the health of human and non-human nature might be permanently preserved and regenerated. Considering age limitations, such education will be extended in all formal education, and will radiate in all spheres of informal education (incorporating the family, the neighborhood, and in centers for sports, culture, art, leisure, etc.).

In a word, such education will promote love and respect for each human and each non-human being or entity existing on the planet (and wherever Humanity might arrive beyond Earth). In light of the third fundamental rule of ethics, deep reflection is undertaken, such that the harmful effects of each action or omission on our part toward non-human nature might be minimized. Such actions or omissions occur when we must feed ourselves at the expense of other beings or non-human entities, or when we modify forever a certain ecosystem by constructing a home or educational or recreational center. In relation to humans, the attitude of love and respect includes behavior that allows for the courteous practice of direct democracy and forms of participatory and representative democracy; that is, always hearing more than is said and arguing not to win, but that the best argument might win (from which will be derived the best action for everyone).

In formal education, we consider these useful guidelines:

- Linking each topic to relevant socio-environmental issues;

- Promoting the rediscovery of knowledge through dialogue and investigation;

- Favoring collective cooperation and never selfish individualism;

- Incorporating the contribution of knowledgeable third parties into exchanges between educator and learners; and

- Always closing the epistemological cycle with the implementation of specific measures (with the participation of educator and learners) in solving the socio-environmental problems addressed.

For community-based informal education with an e-communitarian orientation, we propose the following guidelines. The educators-supporters-activists begin a dialogue with the local community in which they resolve to take a census of the community's main socio-environmental problems. Starting from this census, through dialogue, educators help the community understand how these problems link to the structure of capitalism, and they explain 
the foundations of e-communitarianism. They then discuss with the community where and with whom they can gather knowledge and obtain help for resolving (even partially) some of their problems.

Here, preference is given to cooperative and public agencies over false business aid. With this grounding, the community and educators define the concrete actions needed to resolve the problems prioritized from an e-communitarian perspective. Actions are implemented; the problem is solved. Its solution strengthens the community's self-confidence for seeking solutions for other problems. The educators help the community understand that any selfishly-isolated solution is insufficient for achieving enduring collective satisfaction, and they encourage the community to continue the struggle for more successes of its own, but to integrate that fight not only with help provided to other communities but with national and planetary action in favor of e-communitarianism. 